\title{
Balcones para el aplauso
}

\author{
Tatiana Carolina Chavez \\ Email: tatascaro@hotmail.com
}

Recibido: 10 junio 2020

Evaluado: 12 julio 2020

Publicado: 10 noviembre 2020

\section{Resumen}

La crisis de COVID19, ha resignificado la forma de vida producción y las metodologías de trabajo.: sin embargo, durante este periodo la actitud positiva de la ciudadanía ha aportado significativamente a superar la primera parte de la crisis, apoyando la árdua labor de los agricultores, limpiadores, transportistas, conductores de autobús y metro, reponedores, cajeros de supermercado, policías, sanitarios, y personal de la salud, quienes han formado una una primera línea de lucha para contener el virus y a esto se suma la disciplina de la ciudadanía confinada quienes han agredgado a sus rutinas para demostrar apoyo a la valiente entrega de quienes han permitido mantener la cotideaneidad en nuestras vidas.

El desarrollo de las actividades en el periodo de la crisis de COVID19, ha resignificado la forma de habitar los espacios; evidentemente el adaptarse a las nuevas circunstancias es un reto, ya que se reconceptualiza la idea de público y privado.

Palabras clave: Covid 19; ciudadanía; solidaridad; Barcelona; Bon Pastor; operación Mercedes; monumento 


\section{Abstract}

The COVID19 crisis has redefined the way of life, production and work methodologies: however, during this period, the positive attitude of citizens has contributed significantly to overcoming the first part of the crisis, supporting the arduous work of farmers. , cleaners, transporters, bus and subway drivers, replenishers, supermarket cashiers, policemen, health workers, and health personnel, who have formed a first line of struggle to contain the virus and to this is added the discipline of the confined citizenry who have attacked their routines to show support for the courageous dedication of those who have allowed us to maintain everyday life in our lives.

The development of activities in the period of the COVID19 crisis, has redefined the way of inhabiting spaces; Obviously, the adaptation to new circumstances is a challenge, since the idea of public and private is reconceptualized.

Keywords: Covid 19; citizenship; solidarity; Barcelona; Bon Pastor; operation Mercedes; monument

\section{Resum}

La crisi de COVID19, ha resignificat la forma de vida producció i les metodologies de treball .: però, durant aquest període l'actitud positiva de la ciutadania ha aportat significativament a superar la primera part de la crisi, donant suport a la àrdua tasca dels agricultors, netejadors, transportistes, conductors d'autobús i metro, reposadors, caixers de supermercat, policies, sanitaris, i personal de la salut, que han format una una primera línia de lluita per contenir el virus ia això se suma la disciplina de la ciutadania confinada els que han agredgado a les seves rutines per demostrar suport a la valenta lliurament dels qui han permès mantenir la cotideaneidad en les nostres vides.

El desenvolupament de les activitats en el període de la crisi de COVID19, ha resignificat la forma d'habitar els espais; evidentment el adaptar-se a les noves circumstàncies és un repte, ja que es reconceptualiza la idea de públic i privat.

Paraules clau: Covid 19; ciutadania; solidaritat; Barcelona; Bon Pastor; operació Mercedes; monument

Idea

I. ROL

- Evocar a la comunidad

- Generar integración entre la zona antigua y la zona nueva del barrio

- Mantener el espacio Activo

\section{CIRCUNSTANCIAS}

- Punto de conexión entre la zona antigua y la zona nueva del barrio lo cual demarca una polarización en las actividades

- Terreno Plano con trama regular de $15 \times 15 \mathrm{~m}$

-Propuesta proyectual que incluye la implantacion de bloques de edificios con alturas entre los 16 Y $31 \mathrm{~m}$

\section{INTENCIONES}

- Utilización de varios elementos modulares con diferentes alturas que respondan a la trama 
planteada por el proyecto arquitectónico

- Generar una estructura que conecte dichos elementos

- Marcar recorridos con agua y luz

-Juego de alturas en relación a los balcones

Estudio del espacio y ubicación del monumento

ESTUDIO DEL ESPACIO

ASOLEAMENTO

$\oplus$

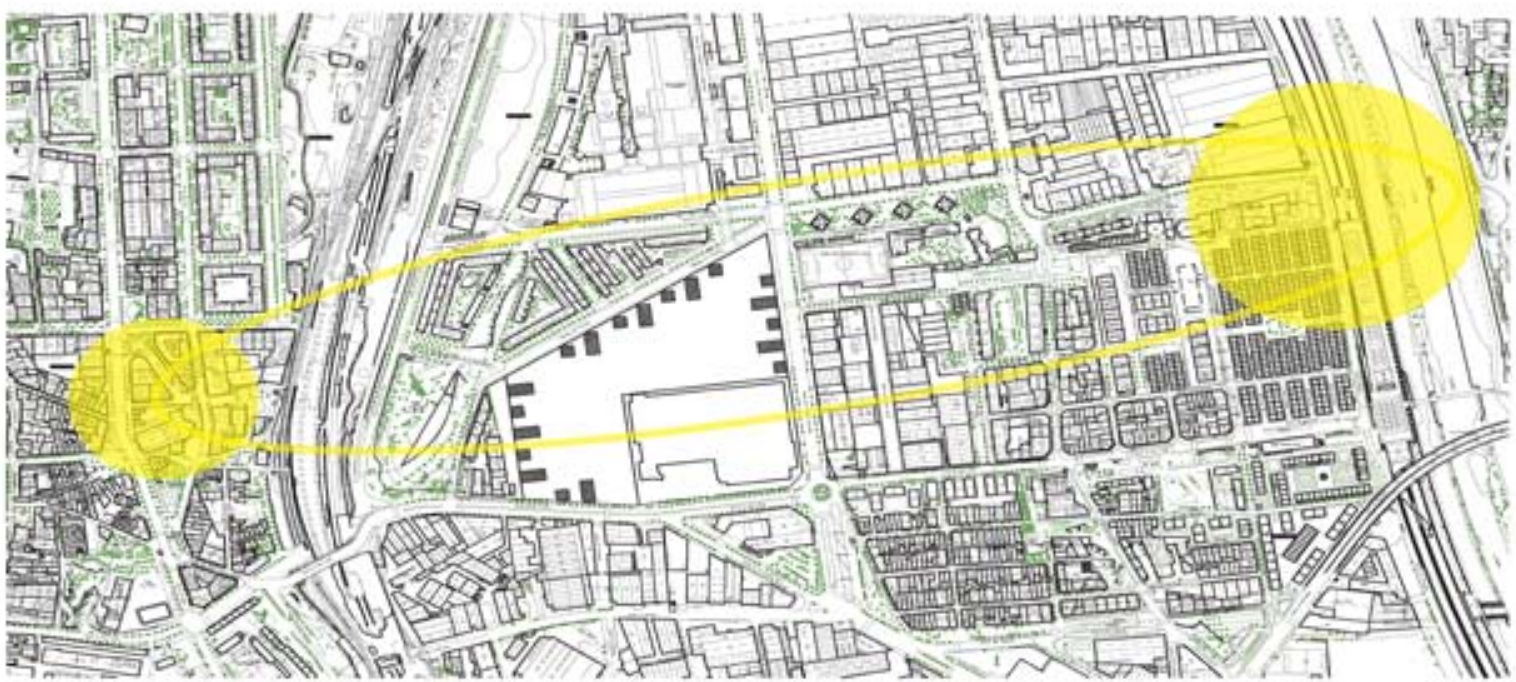

ESTUDIO DEL ESPACIO

ANALLISIS DEEMPLAZAMIENIO

$\frac{\sqrt{0}}{0}$

$\sigma$

(

.




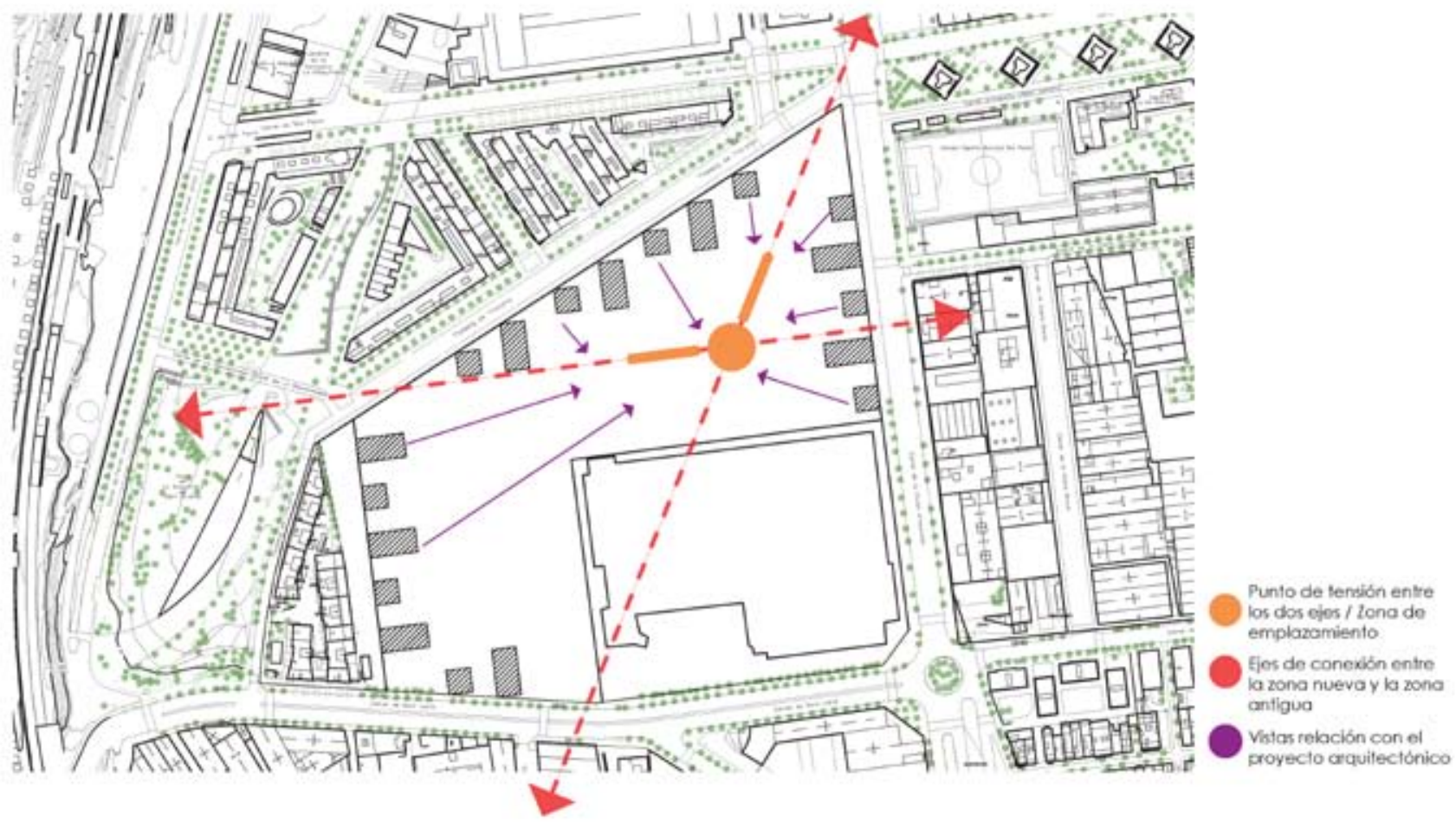

ESTUDIO DEL ESPACIO

EMPLAZAMIENTO

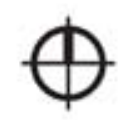

El territorio se compone de dos espacios marcados, que se pueden entender como el Bon Pastor antiguo y el nuevo (la Maquinista Sur), el eplazamiento, busca arficular estos dos espacios para generar un punto de conexión entre ambos, creando así los ejes de eplazamiento del monumento.

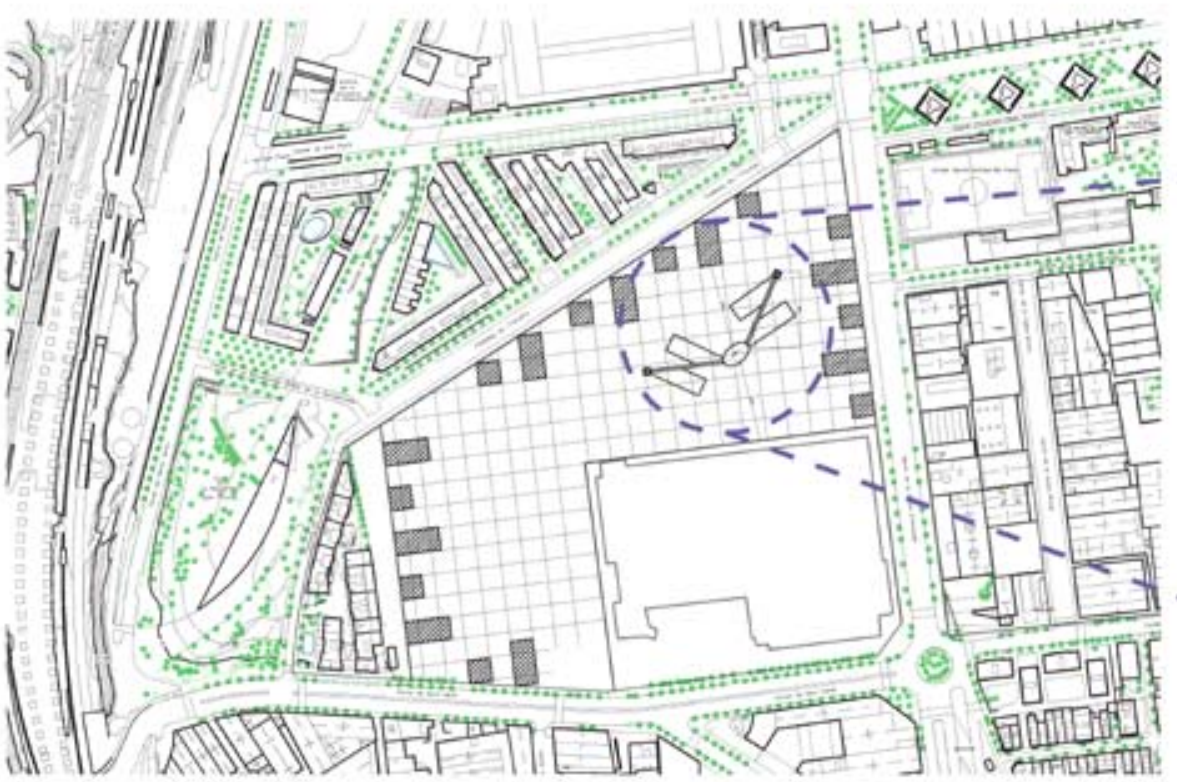

A emplazamiento plantea dos ejes de 50 metros cada uno contadosdesde su articulación que cuenta con un ancho de 20 metros.

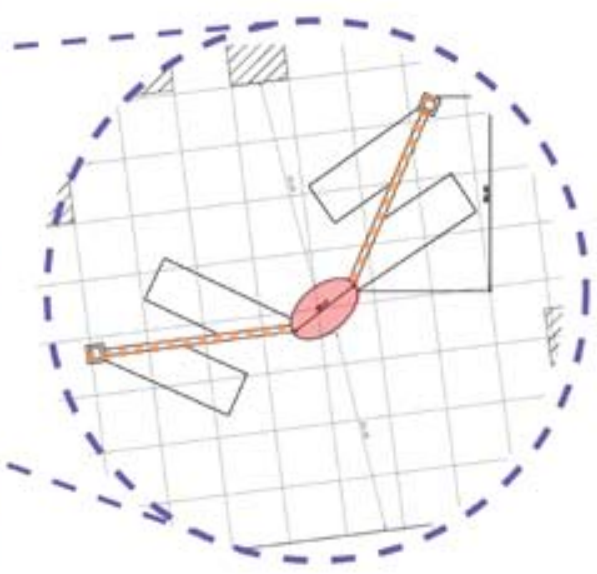


EL MONUMENTO

IDEAA DESARROLLAR

\section{COWHENTO}

La actual crisis de la pandemia del COVID-19 ha cambiado la forma de relacionarnos con los demás, desde el confinamiento se nos ve limitado el contacto cercano con otras personas y de repente nos damos cuenta de que dependemos los unos de los otros: es así. que surgen nuevas dinámicas que nos acercan un poco más como por ejemplo ver que hay frente a nosotros al salir al balcón y reconocernos con los otros.

\section{ROL}

- Evocar a la comunidad

- Generar integración entre la zona antigua y la zona nueva del barrio

- Mantener el espacio Activo

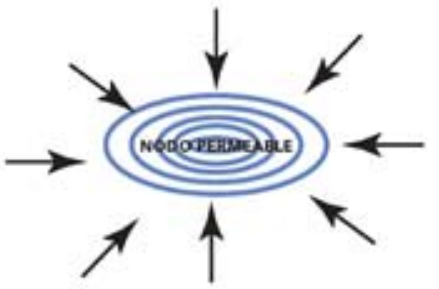

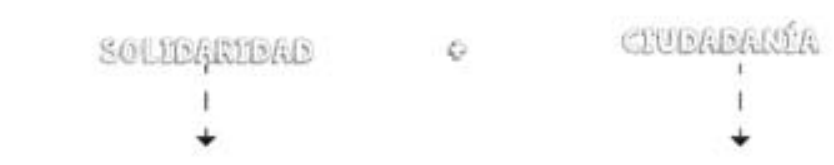

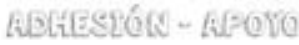

GLUTOO DE RERSORRS

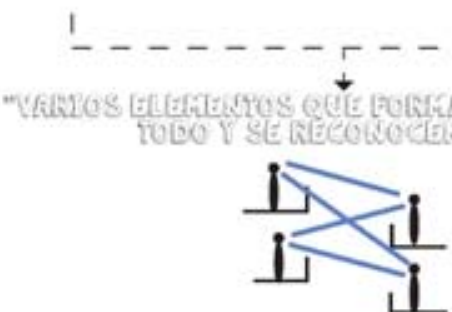

\section{CIRCUNSTANCIAS}

- Punto de conexión entre la zona antigua y la zona nueva del barrio lo cual demarca una polarización en las actividades

- Terreno Plano con frama regular de $15 \times 15 \mathrm{~m}$

-Propuesta proyectual que incluye la implantacion de bloques de edificios con alturas entre los 16 y 31 m

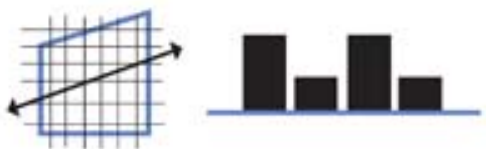

\section{INTENSIONES}

Utilización de varios elementos mociulares con diferentes alturas que respondan a la frama planteada por el proyecto arquitectónico

- Generar una esturctura que conecte dichos elementos

- Marcar recorridos con agua y luz - Juego de alturas en relación a los ba

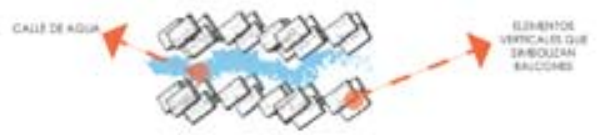

\section{EL MONUMENTO}

DESDE LA FORMALIRACION HASTA SU ESTADO
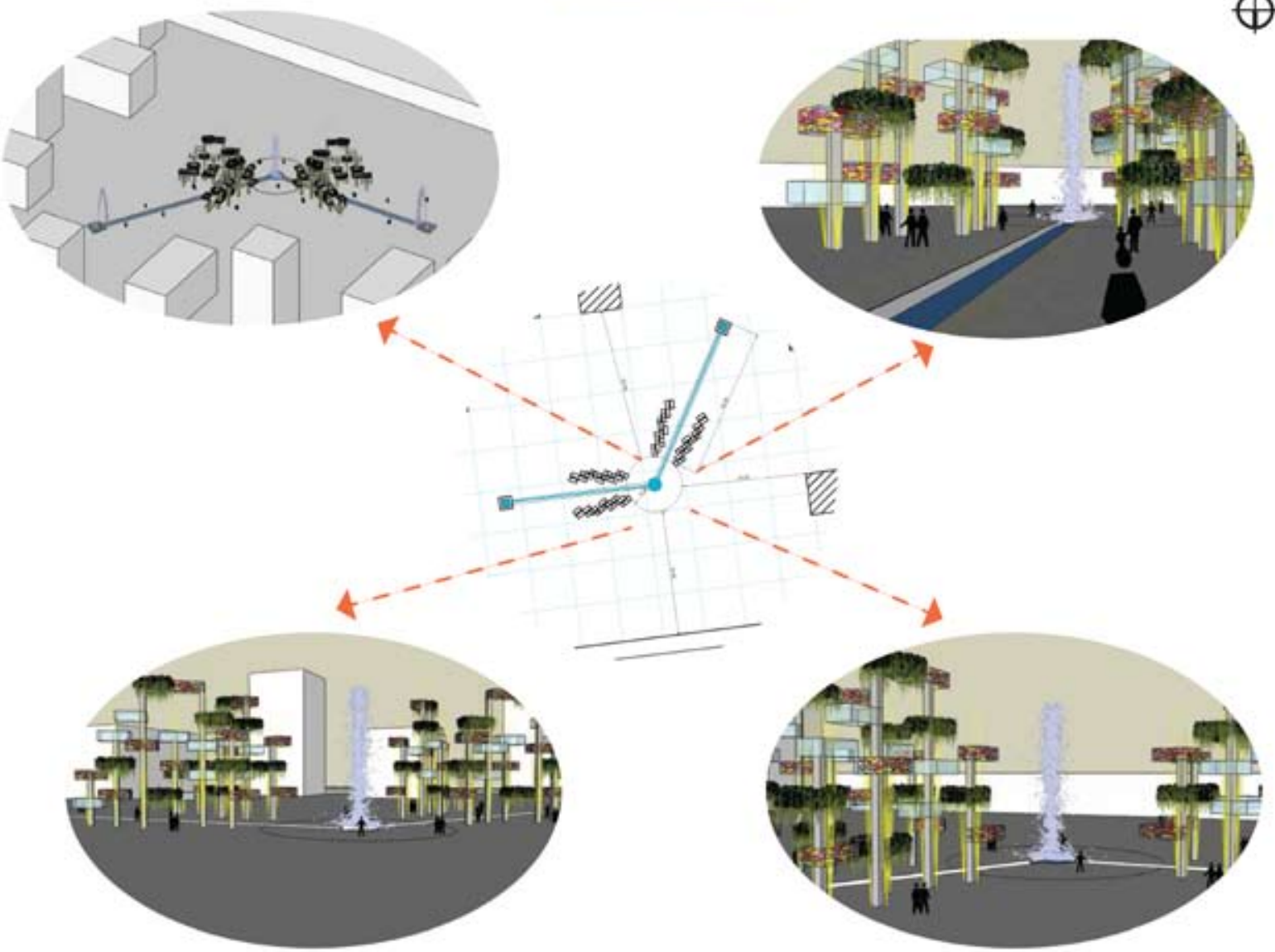

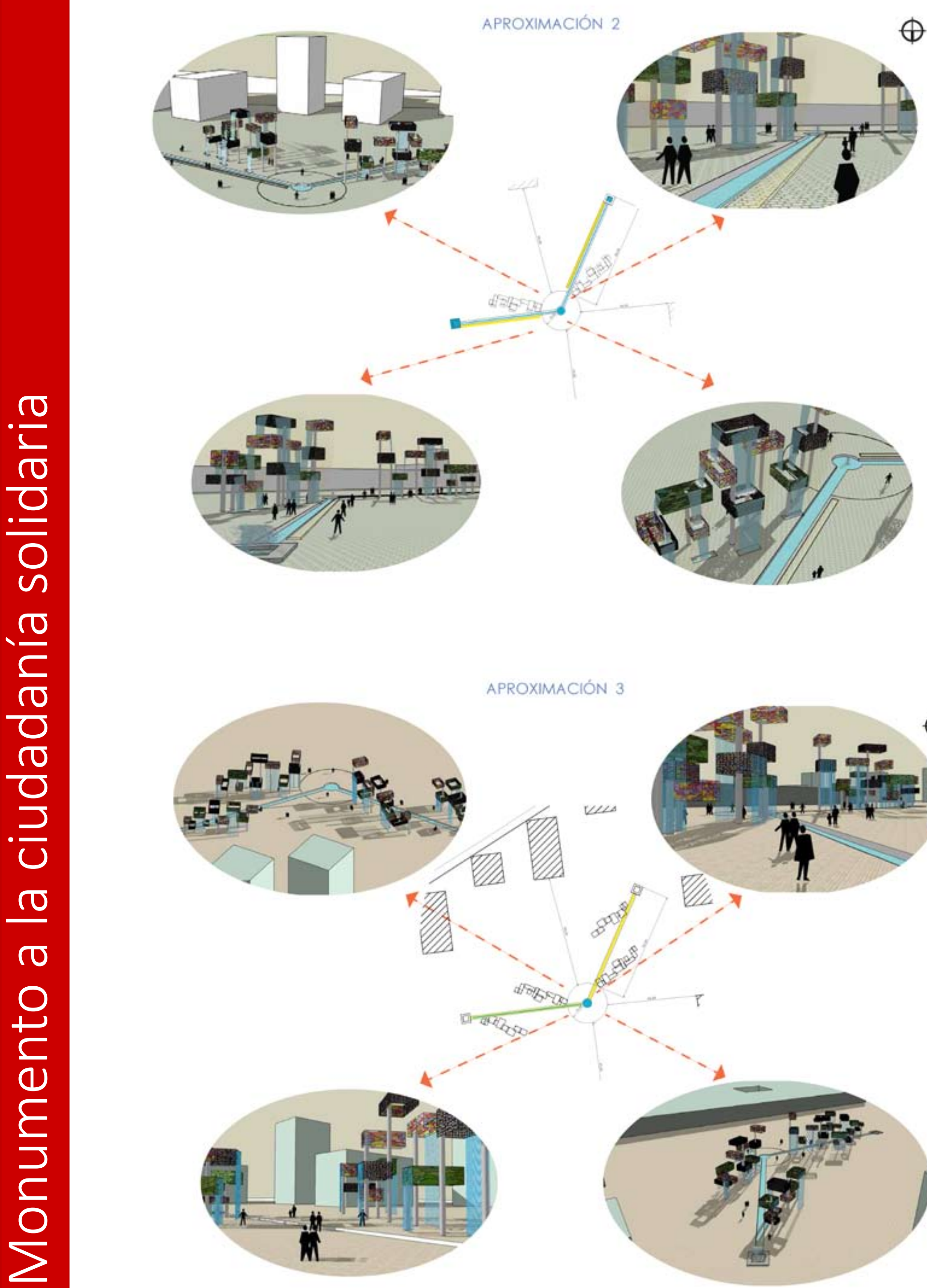

\section{APROXIMACIÓN 3}

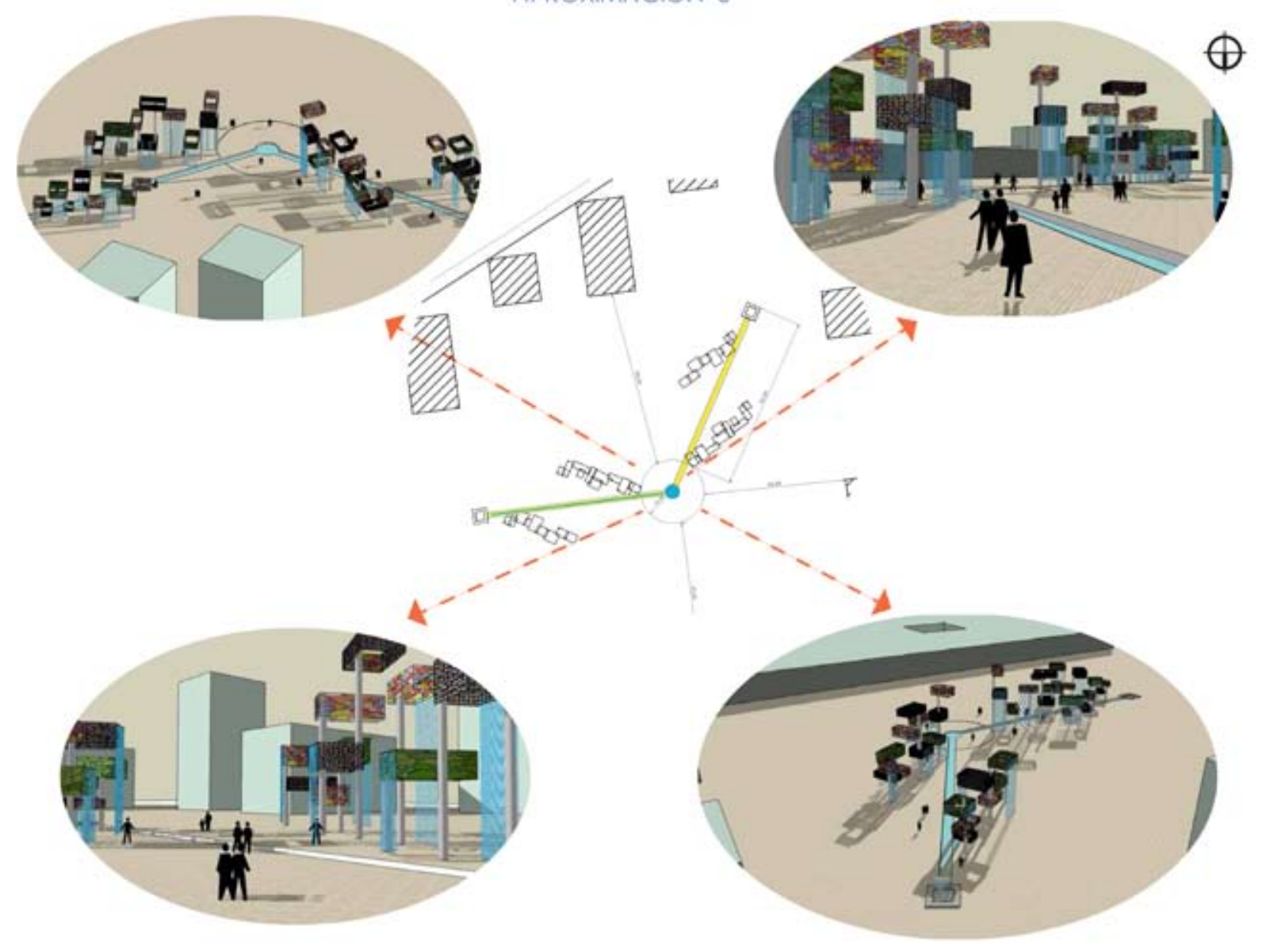


El monumento

EL MONUMENTO

PRESENIACION TECNICA, PLANTA DE EMPLAZAMIENTO
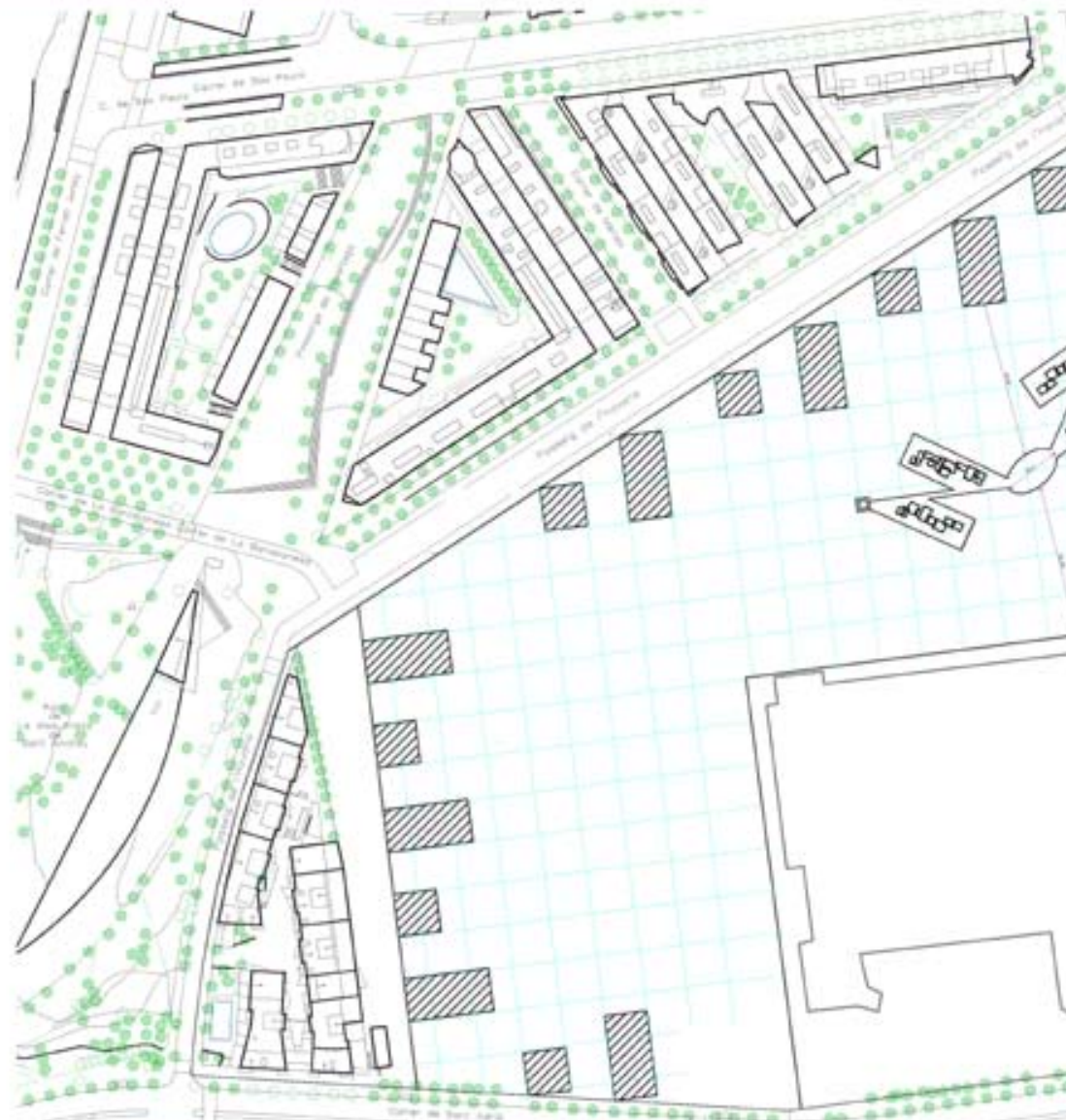

ISA
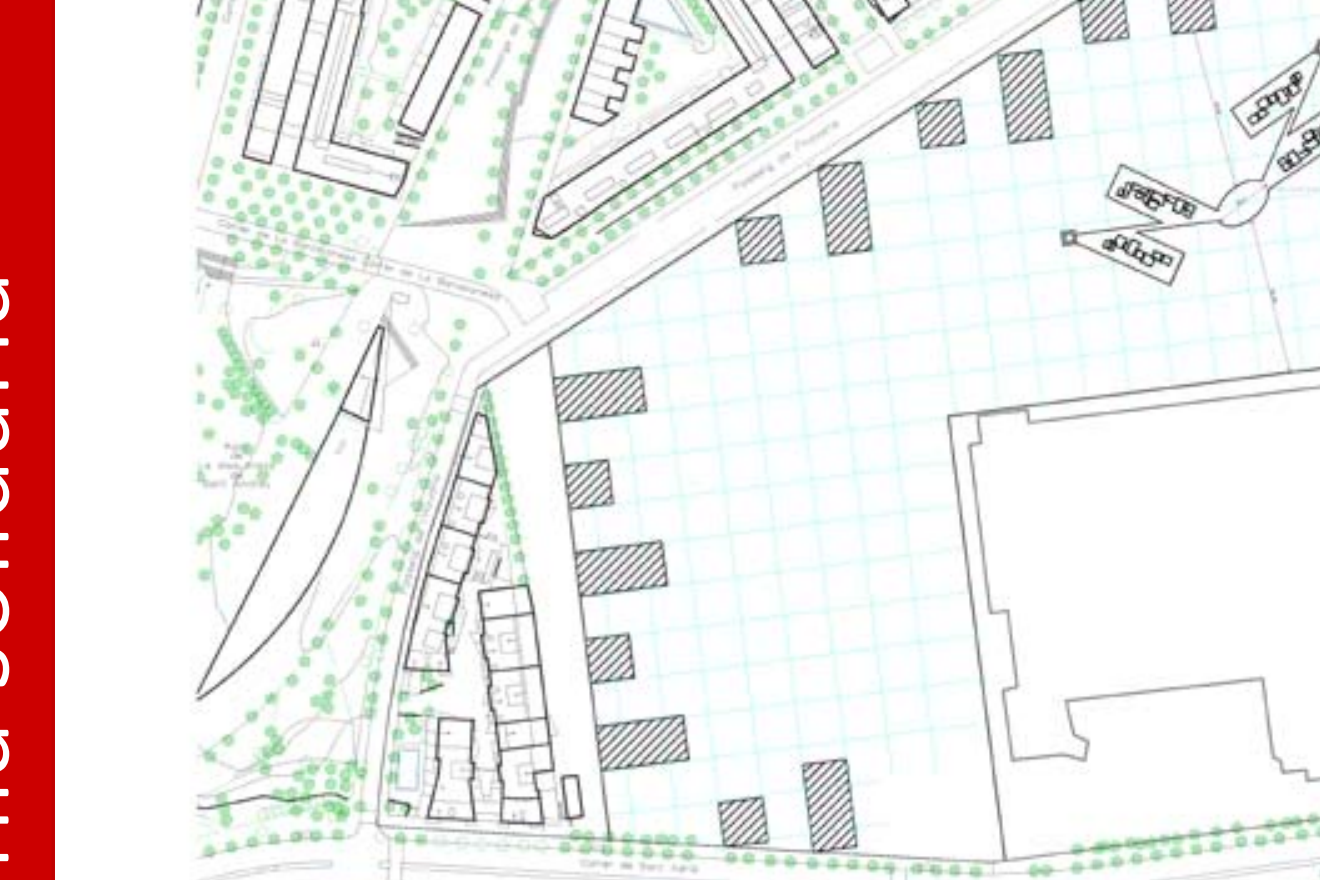

\section{EL MONUMENTO \\ PLANTA DEL MONUMENTO}
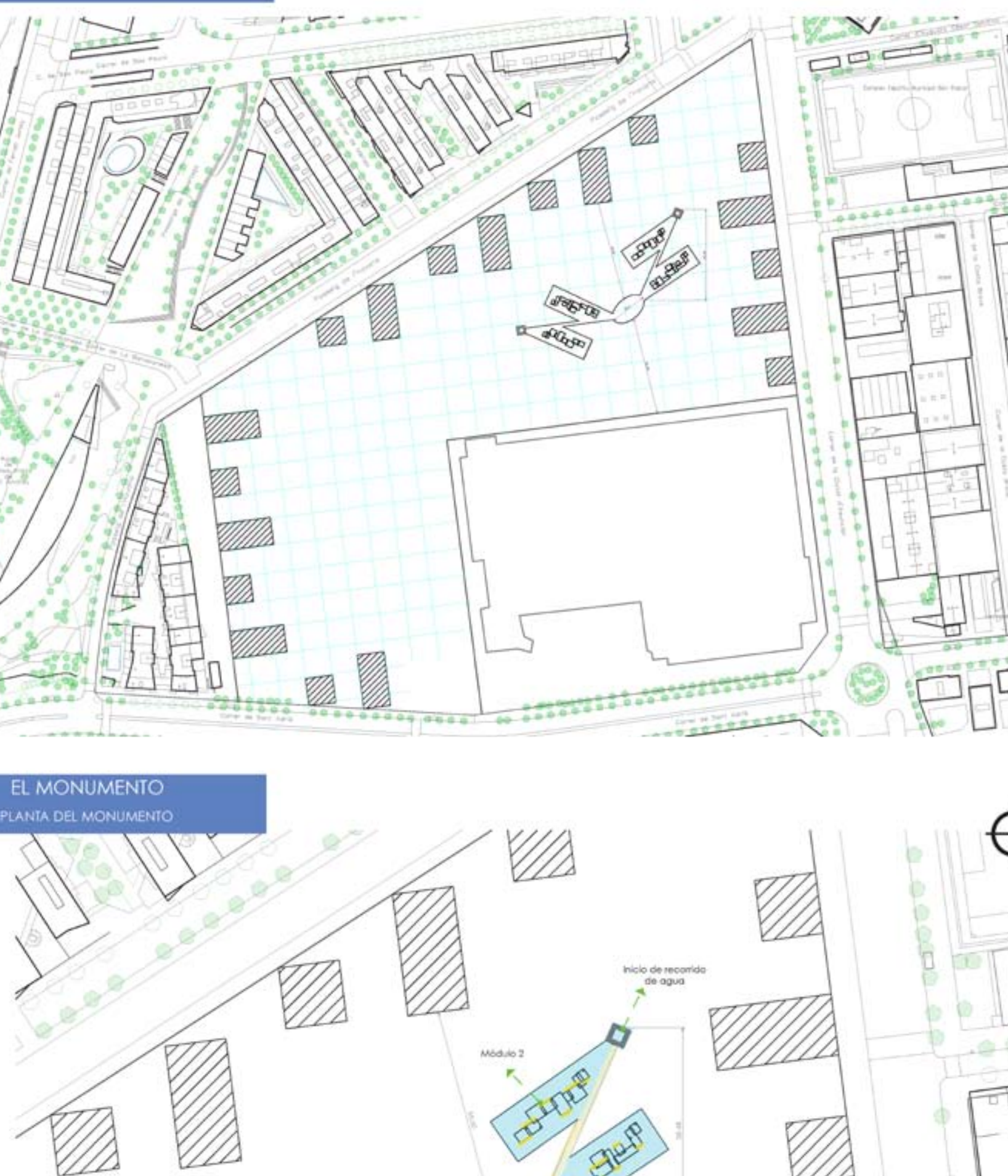

$\bigoplus$

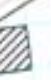


MODULO 1

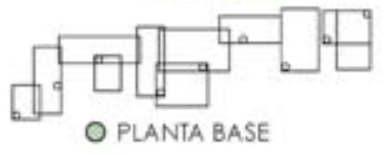

O PLANTA BASE

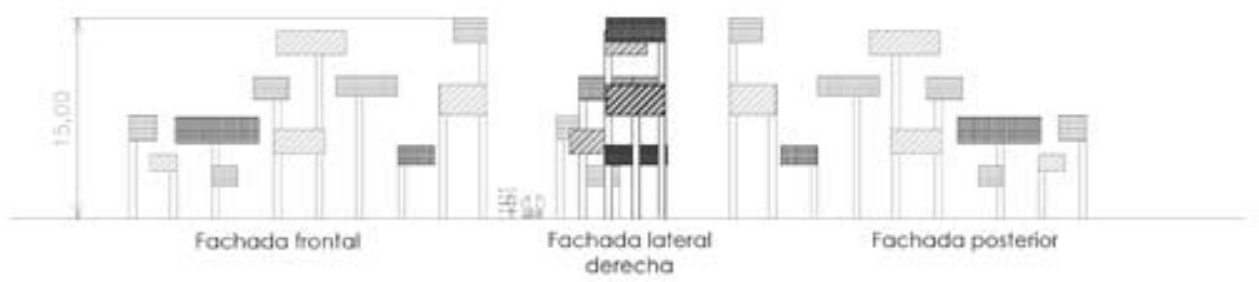

MODULO 2

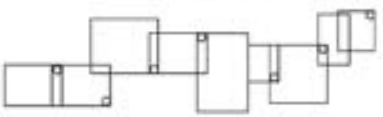

O PLANTA BASE

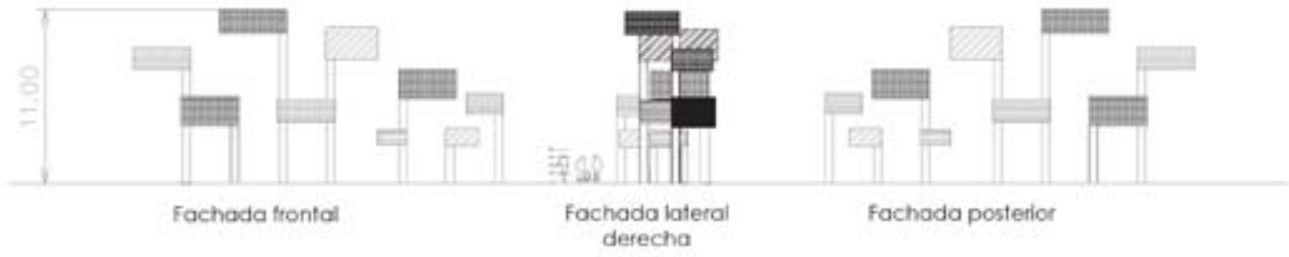

EL MONUMENTO

SECCIONES DEL MONUMENTO Y COTAS DE LOS EREMENIOS

Diferente textura

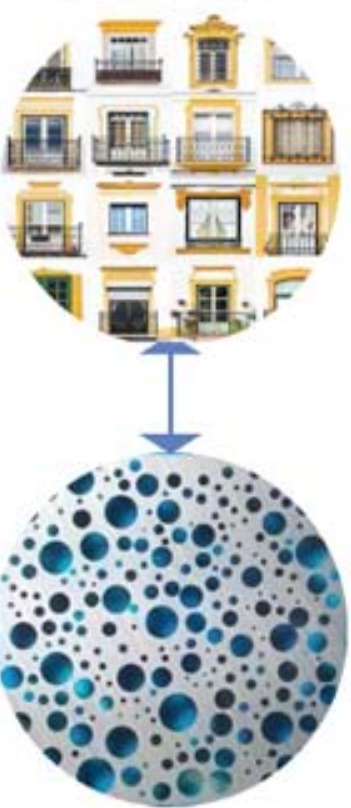

Plataforma que sobresale de la fachada de un edificio a la altura de un vano y estó protegida por una barandilia o un muro bajo.

\section{BQUE ES UT BLLEOW}

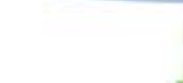

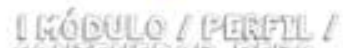

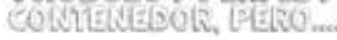
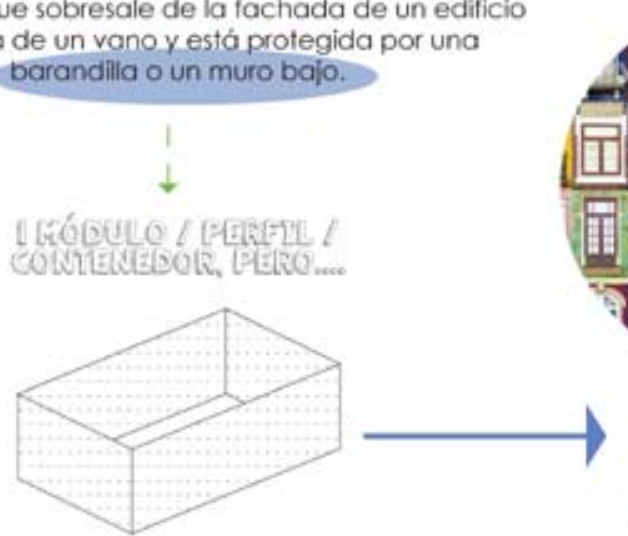

Diferente color

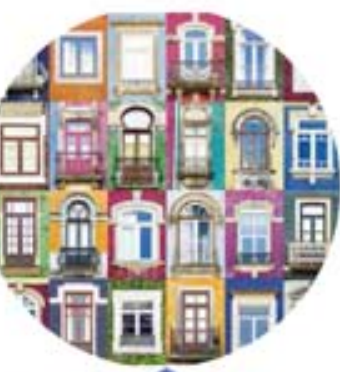

.
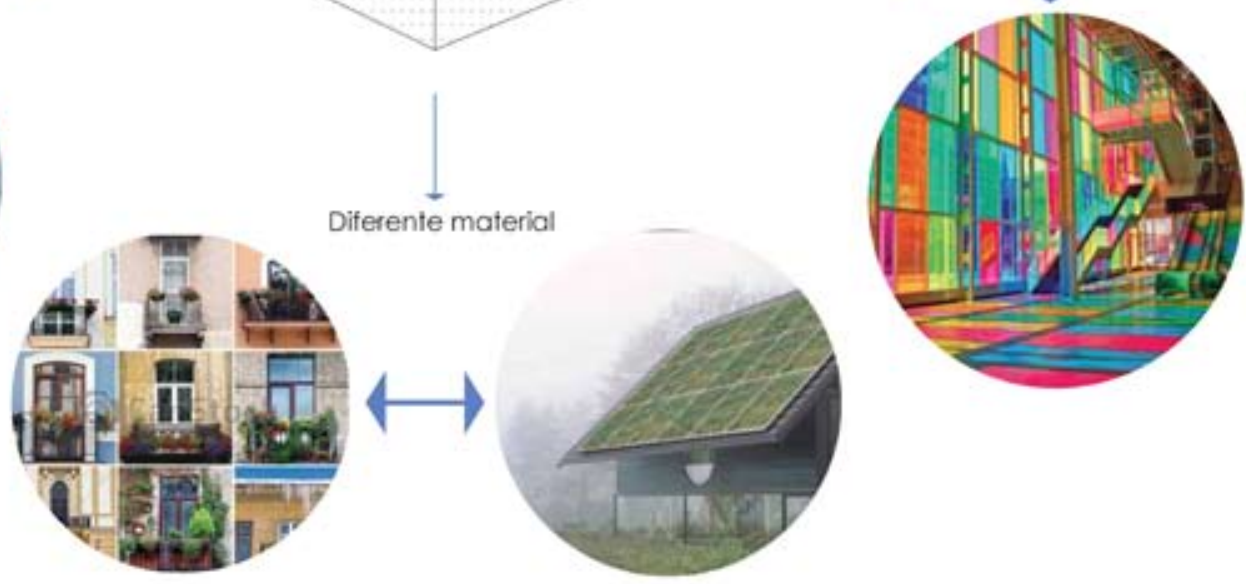
MODULO 1/CAIDA DE AGUA TIPO LLUVIA

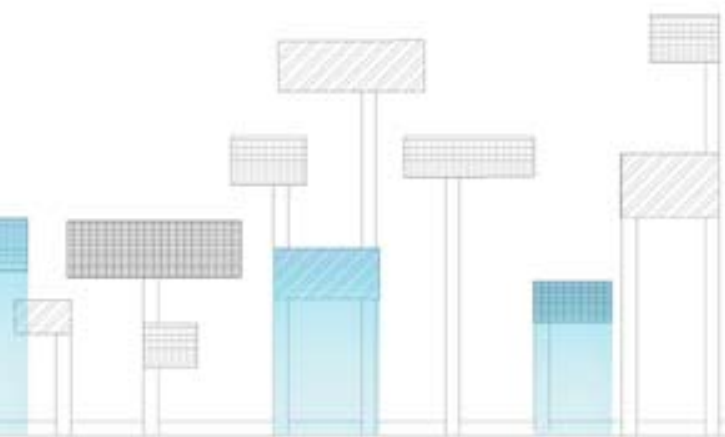

FACHADA FRONTAL

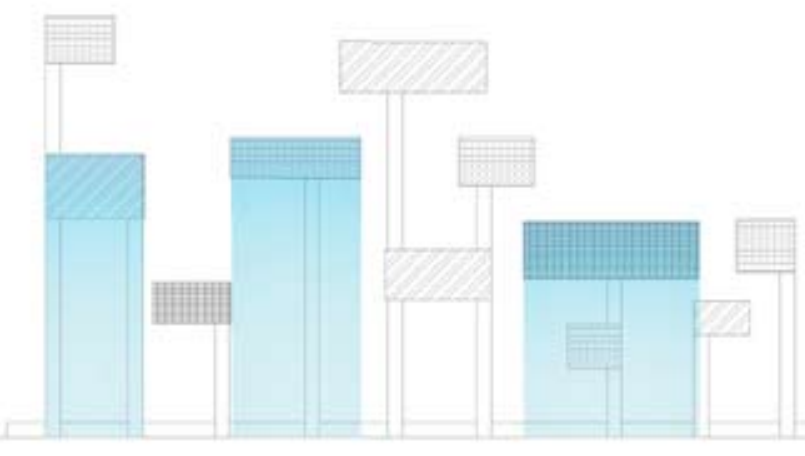

FACHADA POSTERIOR

MODULO 2 / CAIDA DE AGUA TIPO LLUVIA

MODULO 1 / PERFILES METÁLICOS SUPERIORES EINFERIORES EN LOS CUALES SE ALOJAN TIRAS DE LED RGB DIGIIALES CONIROLADAS PUNIO POR PUNIO

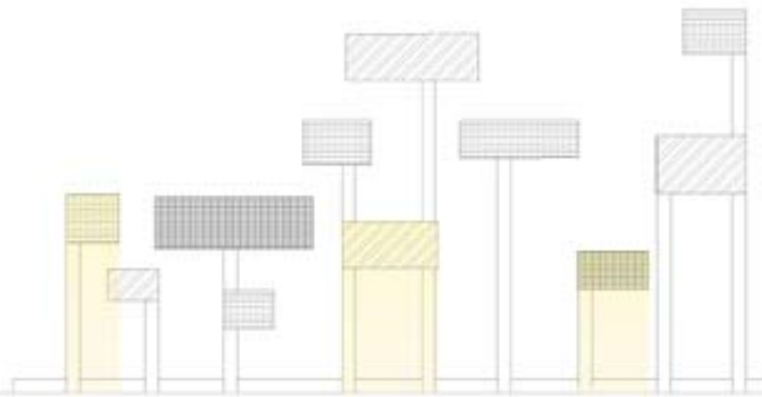

FACHADA FRONIAL

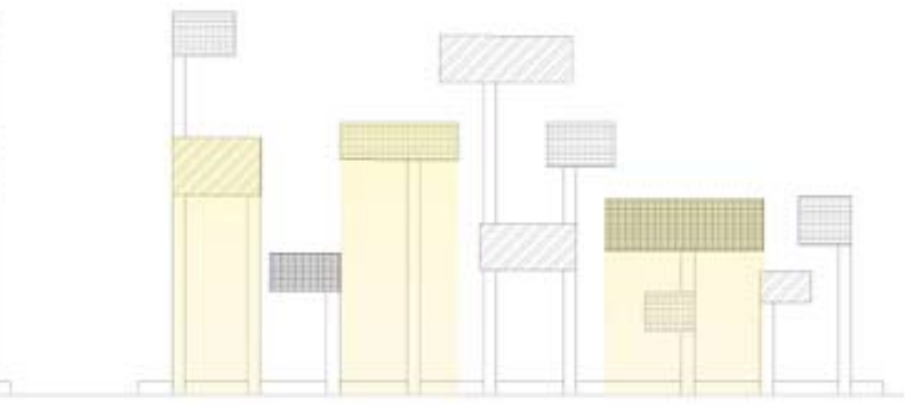

FACHADA POSTERIOR

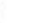

MODULO 2 / PERFILS METÁLICOS SUPERIORES EINFERIORES EN LOS CUALES SE ALOJAN TIRAS DE LED RGB DIGITALES CONTROLADAS PUNTO POR PUNTO

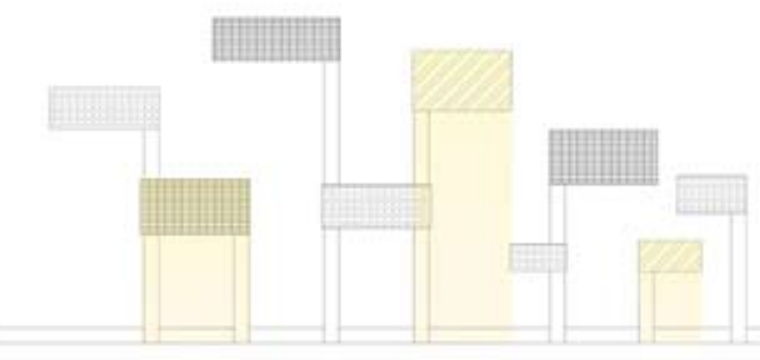

FACHADA FRONTAL 
Implantaciones y fotomontajes

IMPLANTACIONES Y FOTOMONTAJES

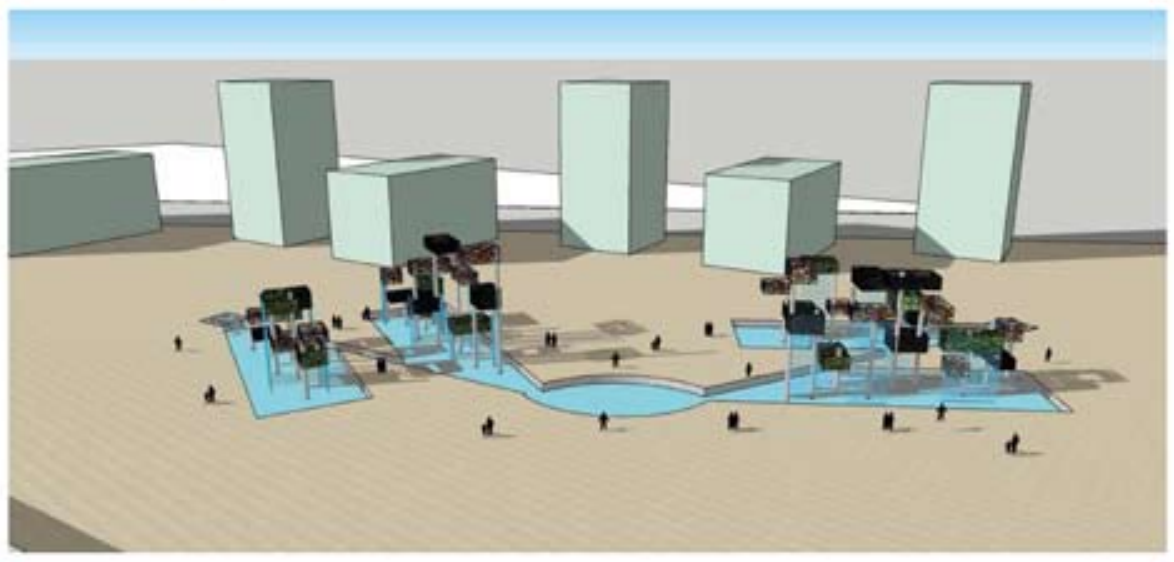

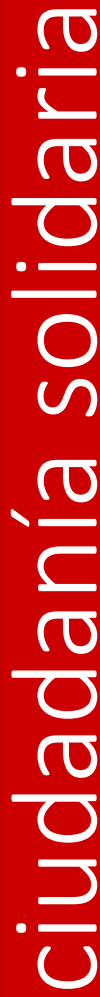

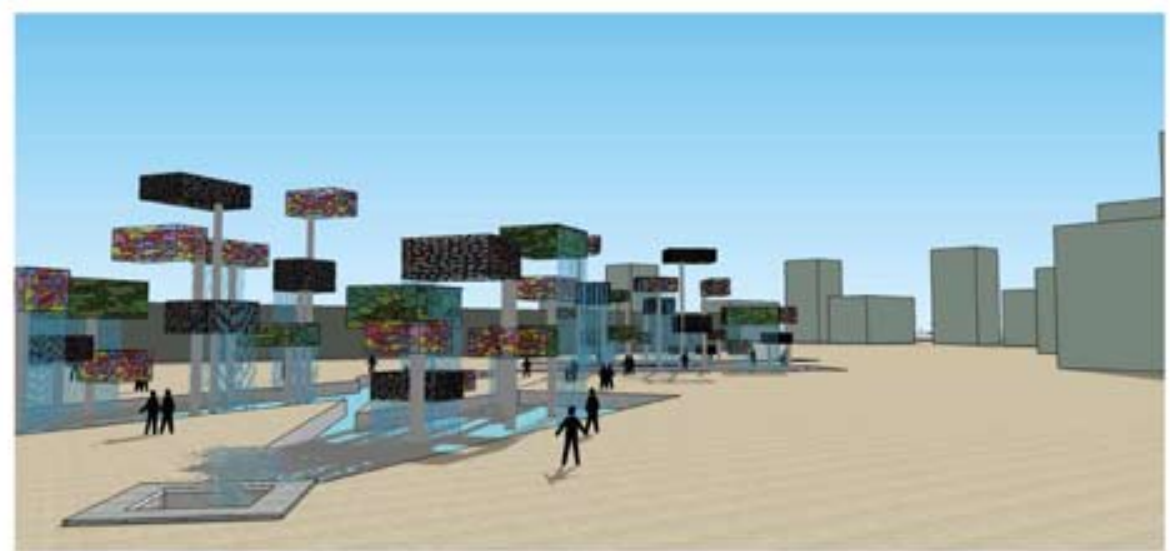

IMPLANTACIONES Y FOTOMONTAUES
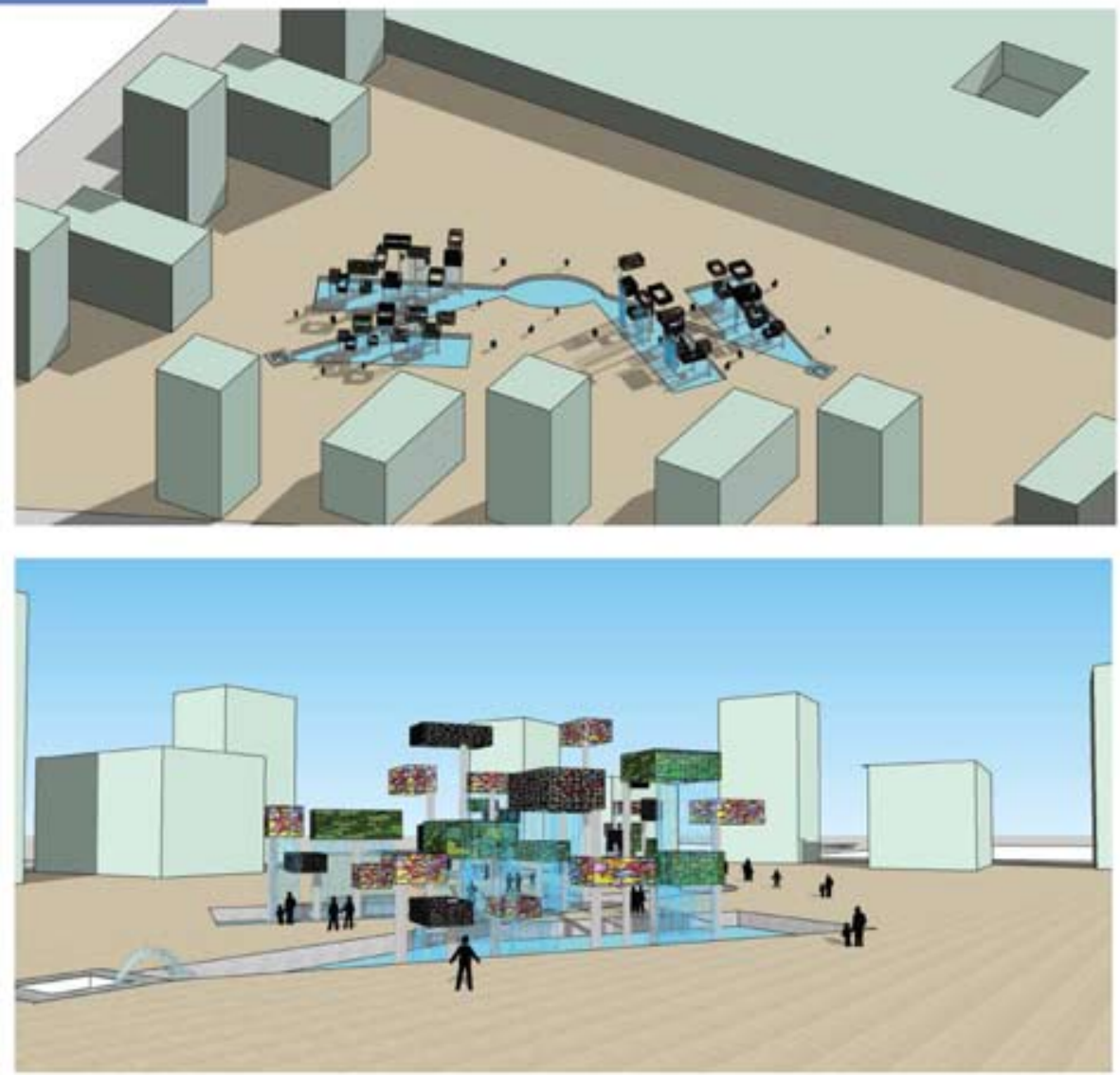

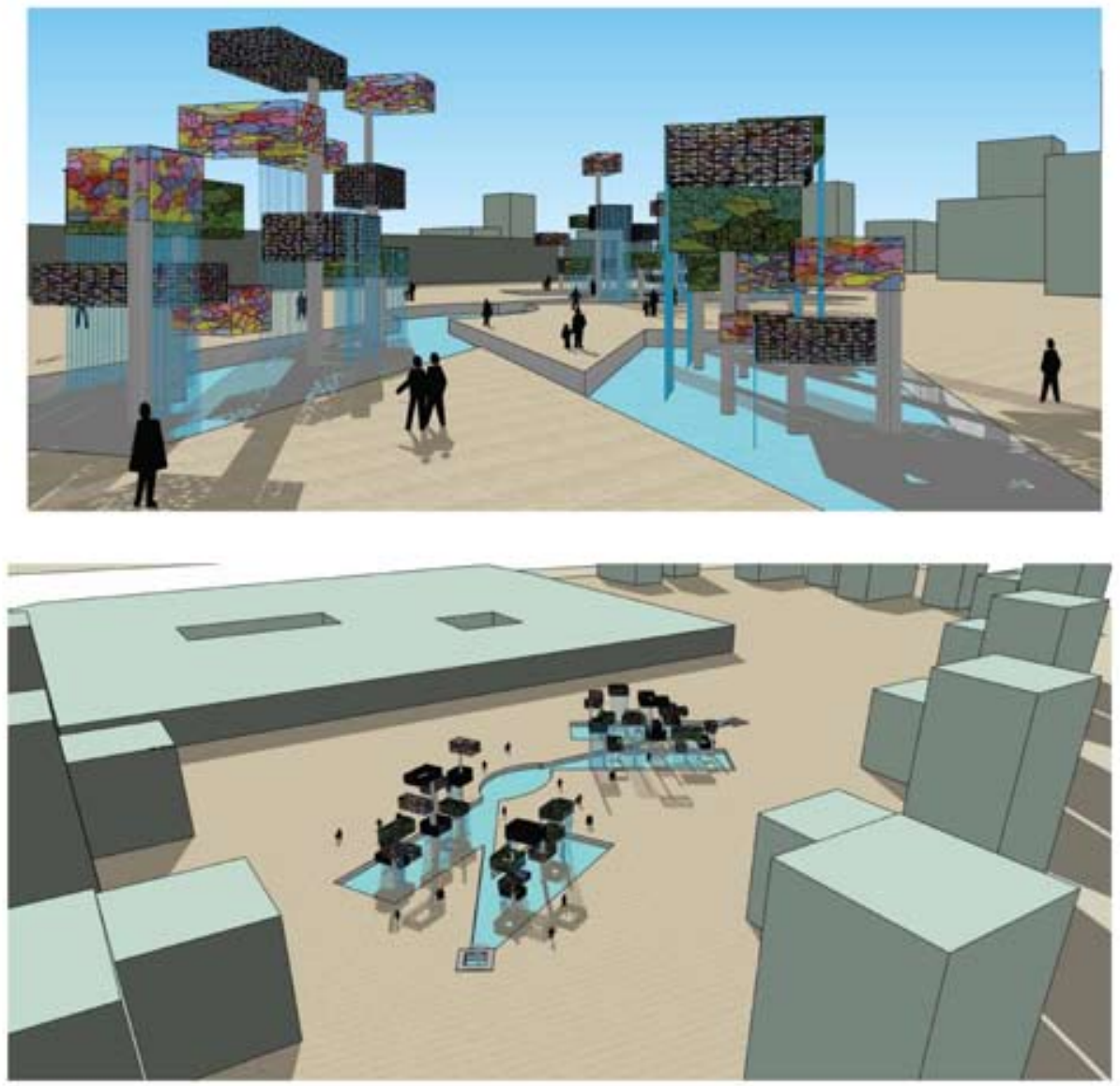

\section{Referencias}

AJUNTAMENT DE BARCELONA. n.d. "Estrategia Para La Transición Energética | Ecología, Urbanismo, Infraestructuras y Movilidad." Accessed June 25, 2020. https://ajuntament.barcelona.cat/ecologiaurbana/es/que-hacemos-y-porque/energia-y-cambio-climatico/estrategia-transicion-energetica.

AJUNTAMENT DE BARCELONA. n.d. "Plan de Renovación Integral Del Alumbrado | Ecología, Urbanismo, Infraestructuras y Movilidad." Accessed June 25, 2020. https://ajuntament.barcelona.cat/ ecologiaurbana/es/que-hacemos-y-porque/espacio-publicode- calidad/plan-director-de-iluminacion.

ANGOSTO, SALVADOR (2019). Mapping the History of a Territory: Bon Pastor (Barcelona) - Social Remembrance and Heritage Project. Acta Universitatis Lodziensis. Folia Philsophica-Ethica-Aesthetica-Practica, 33, 37-55. https://doi.org/10.18778/0208-6107.33.03

BENAVIDES, LUIS. 2020. "Bon Pastor Pide Más Verde En Los Solares de La Mercedes-Benz." EL PERIÓDICO. 2020. https://www.elperiodico.com/es/barcelona/20200121/futuro-fabrica mercedesbenz-bon-pastorbarcelona- 7813857.

CIUTAT HORIZONTAL, LA. n.d. "Imágenes | La Ciutat Horitzontal." Accessed June 21, 2020. http:// laciutathoritzontal.org/es/imatges.

CONSORCIO BESÒS. n.d. "El Besòs Marca Su Agenda | Consorcio Del Besòs." Accessed June 21, 2020. https://consorcibesos.cat/besos-agenda/.

PLA ESTRATÈGIC METROPOlitÀ DE BARCELONA. 2015. "La Sagrera- Sant Andreu: Sistema Ferroviario y Proyecto Urbano." 
PLA ESTRATÈGIC METROPOLITÀ DE BARCELONA. 2015.https://pemb.cat/es/proyectos estrategicos/la_sagrera_sant_andreu_sistema_ferroviario_y_proyecto_urbano/70/.

RECA. n.d. "RECA Chapa Perforada | Chapas Perforadas." Accessed June 25, 2020. https://www. reca.es/.

REMESAR, Antoni; CRESPO, Bibiana. (2017). The White Centre. A first step of the civic remembrance system in Bon pastor (Barcelona). Acta Universitatis Lodziensis. Folia Philsophica-EthicaAesthetica-Practica, 30, 9-39. http://dx.doi.org/10.18778/0208-6107.30.02

REMESAR, Antoni; CRESPO, Bibiana. (2018). El sistema espacial de Memòria cívica al barri de Bon Pastor (Barcelona). Estudi del Centre Blanco. On the W@terfront, 60(4), 3-51. https://raco.cat/ index.php/Waterfront/article/view/334982/425651

REMESAR, A., \& VERGEL FARO, J. (2020). Acceder a la gestión de lo simbólico. Un derecho ciudadano. on the w@terfront. Public Art.Urban Design.Civic Participation.Urban Regeneration, 62(7), 39-56. doi:https://doi.org/10.1344/waterfront2020.62.6.11

SALAS, X. (2016). Bon Pastor (Barcelona) Un territorio en construcción. on the w@terfront. Public Art.Urban Design.Civic Participation.Urban Regeneration, 43, 7-46. Recuperado de https://revistes.ub.edu/index.php/waterfront/article/view/18685

VALENCIA, NICOLÁS. 2017. "Rec Comtal, Un Proyecto Paisajístico Para Restaurar El Histórico Canal de Riego de Barcelona | Plataforma Arquitectura." PLATAFORMA ARQUITECTURA. 2017. https:// www.plataformaarquitectura.cl/cl/870165/rec-comtal-un-proyecto-paisajistico-para-restaurar-elhistorico-canal-de-riego-de-barcelona.

VÁZQUEZ DE LA ROSA, H., \& BASTIDAS MORA, S. (2019). Plan de Integración del Plano Vertical al Paisaje Urbano.. on the w@terfront. Public Art.Urban Design.Civic Participation.Urban Regeneration, 61(3), 3-46. doi:https://doi.org/10.1344/waterfront2019.61.6.3

VERGEL, Javier. (2017). Ciudad, comunicación, identidad y participación: Hacia un sistema de información para el Barrio del Bon Pastor [M.A., Universitat de Barcelona]. http://hdl.handle. net/2445/117925 
